\title{
A new delphinid from the lower Pliocene of the North Sea and the early radiations of true dolphins
}

\author{
Alice Belluzzo $^{1}$ and Olivier Lambert ${ }^{2}$ \\ ${ }^{1}$ Dipartimento di Scienze della Terra, Università di Pisa, Pisa, Italy \\ ${ }^{2}$ D.O. Terre et Histoire de la Vie, Institut royal des Sciences naturelles de Belgique, Brussels, Belgium
}

Correspondence: Olivier Lambert (olambert@naturalsciences.be)

Received: 14 January 2021 - Revised: 23 February 2021 - Accepted: 2 March 2021 - Published: 7 April 2021

\begin{abstract}
With a remarkable exception for the Mediterranean, the worldwide Pliocene record of true dolphins (Cetacea, Odontoceti, Delphinidae) remains scarce, in stark contrast with the large number of extant species testifying to the evolutionary success of this family. Based on a fragmentary skull discovered in lower Pliocene deposits (Zanclean, 5 to $4.4 \mathrm{Ma}$ ) of the Kattendijk Formation in the Antwerp harbour (Belgium, southern margin of the North Sea basin), we describe here a new delphinid species, Pliodelphis doelensis gen. et sp. nov. This small dolphin with cranial dimensions in the range of the short-beaked common dolphin Delphinus delphis can be distinguished from other extinct and extant delphinids by a combination of cranial features including the maxilla being significantly narrower than the premaxilla at a short distance anterior to the antorbital notch in dorsal view, the maximum opening of the mesorostral groove being located at the level of the antorbital notches, a transversely wide and anteroposteriorly long dorsal exposure of the presphenoid anterior to the bony nares, and all dorsal infraorbital foramina being located posterior to the premaxillary foramina. $P$. doelensis constitutes the first member of the family described from the early Pliocene of the North Sea basin and, for the whole North Atlantic realm, only the third outside the Mediterranean. This new record contributes thus to our understanding of the poorly known Pliocene radiation(s) of true dolphins.
\end{abstract}

\section{Introduction}

Nowadays, the family Delphinidae (true dolphins) constitutes the most speciose cetacean family, including a highly disparate range of small, medium, and large-size species from at least three subfamilies, occupying many marine and even some freshwater habitats worldwide (Jefferson and LeDuc, 2018; Galatius et al., 2020; McGowen et al., 2020). The evolutionary success of this clade has been tentatively correlated with a number of extrinsic and intrinsic features, including for example brain size increase, improved echolocation abilities, and key innovations at the level of the vertebral column (Marino et al., 2004; Bianucci, 2013, and references therein; Gillet et al., 2019). With an origin of crown Delphinidae estimated by molecular analyses at $12-9 \mathrm{Ma}$ (e.g. Steeman et al., 2009; McGowen et al., 2020), one could expect a rich late Miocene fossil record. Surprisingly, this is not the case; delphinids from the Tortonian and, to an even greater extent, from the Messinian remain scarce (Barnes, 1976; Murakami et al., 2014). This contrasts markedly with the Pliocene record, which, although displaying an uneven geographic distribution, reveals a relatively high number of extinct species, testifying to an explosive Pliocene to Pleistocene delphinid radiation (e.g. Bianucci, 1996, 2005, 2013; Fordyce et al., 2002; Whitmore and Kaltenbach, 2008; Aguirre-Fernández et al., 2009; Boessenecker, 2013; Bohrer do Amaral et al., 2018). Focusing on the North Sea basin, though at least nine extant delphinid species are regularly observed there (Ridgway and Harrison, 1994, 1999), the delphinid fossil record remains limited, though with some significant late Pliocene to Pleistocene finds (e.g. Post and Bosselaers, 2005; Post and Kompanje, 2010).

Dated from the Zanclean (De Schepper et al., 2009), marine deposits of the Kattendijk Formation, in the area of Antwerp (Belgium, southern margin of the North Sea basin), yielded many marine mammal remains, comprising pinnipeds (earless seals; Ray, 1976, but see comments in Dewaele et al., 2018) and mysticetes (baleen whales), 
with for example the recently described balaenopterids (rorquals) Fragilicetus velponi and Protororqualus wilfriedneesi and the diminutive balaenid (right whale) Balaenella brachyrhynus (Bisconti, 2005; Bisconti and Bosselaers, 2016, 2020). Odontocete cranial material is scarce in this unit, and until now no more than three taxa, the phocoenid (porpoise) Brabocetus gigaseorum, an indeterminate monodontid (narwhal and beluga family), and the ziphiid (beaked whale) Mesoplodon posti have been described (Lambert and Gigase, 2007; Colpaert et al., 2015; Lambert and Louwye, 2016). Considering the large quantity and diversity of odontocete ear bones recovered from the different Pliocene base gravels of the Antwerp area (e.g. at the base of the Kattendijk Formation and of the overlying Lillo Formation; personal observation, 2020), the toothed whale, and more specifically delphinid, diversity for the early Pliocene of the southern margin of the North Sea basin is currently most likely underestimated. In the present work we describe and compare a new delphinid skull from the Kattendijk Formation which contributes to our knowledge of the Pliocene delphinid radiation(s).

\section{Material and methods}

\subsection{Studied specimen}

The main specimen studied here is a partial odontocete skull, IRSNB M.2330, found in layers of the Kattendijk Formation in the Deurganck Dock (Doel, north of Belgium; Fig. 1). The specimen was discovered in non-indurated sand and collected with the surrounding sediment. Cranial bones were broken in pieces due to contacts with dock excavation machines. Sieving of the sediment allowed for the recovery of smaller bone pieces. After cleaning and consolidation, fragments showing fresh break surfaces could be glued together. No clear contact could be found between the two main pieces, on the one hand the rostrum base and facial region and on the other hand the partial basicranium and occipital shield.

\subsection{Specimens for comparison}

For the comparison of the main fossil skull of this study, IRSNB M.2330, we directly examined the following specimens of extant and extinct delphinids: Australodelphis mirus AGSO CPC 25730 (temporarily housed at OU; extinct); Cephalorhynchus commersonii IRSNB 21143, MNHN 18.106; Delphinidae indet. LACM 6501-52147 (extinct); Delphinus delphis IRSNB 5085, 12843; Globicephala macrorhynchus IRSNB 1513; Globicephala melas IRSNB 1514C; Grampus griseus IRSNB 1518, MNHN A3248; Lagenorhynchus acutus IRSNB 1527; Lagenorhynchus harmatuki USNM 206098 (extinct); Lagenorhynchus obscurus IRSNB 21371; Orcaella brevirostris IRSNB 1512; Orcinus orca 1511B; Sotalia fluviatilis IRSNB 1516; Sotalia

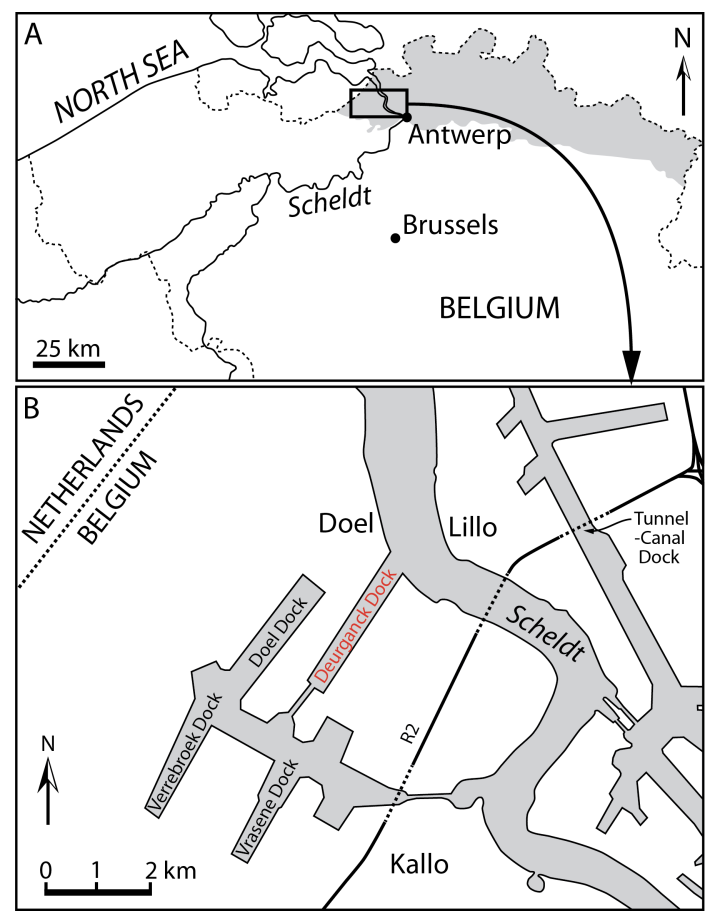

Figure 1. Locality maps of Antwerp in the north of Belgium and the Deurganck Dock where the specimen studied here (IRSNB M.2330) was discovered, in the Antwerp harbour, as well as other neighbouring docks and a tunnel where geological sections have been studied. Modified from Bisconti et al. (2017).

guianensis RMNH 18166, 22257, 22258; Steno bredanensis IRSNB 1515B, NNML 31176, 31177, 31181; Stenella attenuata IRSNB 9323, NNML 21637; Stenella coeruleoalba IRSNB 26517; Stenella longirostris NNML 8676; Stenella rayi USNM 182930 (extinct); and Tursiops truncatus IRSNB 1517B, 20141, ZLV 1572. Other comparisons were done using photos provided by colleagues (especially Giovanni Bianucci) and data from the literature (e.g. Perrin, 1975; Arnold and Heinsohn, 1996; Bianucci, 1996, 2005, 2013, Aguirre-Fernández et al., 2009; Mead and Fordyce, 2009; Murakami et al., 2014; Kimura and Hasegawa, 2020, and references therein).

Several extinct delphinid species have been tentatively referred to extant genera (Lagenorhynchus harmatuki, Orcinus citoniensis, Stenella giulii, Stenella rayi, Tursiops oligodon, and Tursiops osennae). Although not yet confirmed by phylogenetic analyses or by lists of synapomorphies, we provisionally retain the original referrals for most species pending a detailed reassessment of their affinities (see for example Post and Bosselaers, 2005, for comments on the status of T. oligodon and Bianucci et al., 2009, for the referral of the species $S$. giulii to the new genus Etruridelphis). 


\subsection{Institutional abbreviations}

1. AGSO CPC - Australian Geological Survey Organisation, Commonwealth Palaeontological Collections

2. BM - Natural History Museum, London, UK

3. GMNH - Gunma Museum of Natural History, Tomioka, Gunma, Japan

4. HMH - Historical Museum of Hokkaido, Hokkaido, Japan

5. IRSNB - Institut royal des Sciences naturelles de Belgique, Brussels, Belgium

6. LACM - Natural History Museum of Los Angeles County, Los Angeles, USA

7. MB - Museo Giovanni Capellini dell’Università di Bologna, Bologna, Italy

8. MNHN - Muséum national d'Histoire naturelle, Paris, France

9. MP - Museo di Storia Naturale e del Territorio Certosa di Calci dell'Università di Pisa, Calci, Italy

10. OU - Geology Museum, University of Otago, Dunedin, New Zealand

11. NNML - Naturalis, Leiden, The Netherlands

12. SMNK - Staatliches Museum für Naturkunde, Karlsruhe, Germany

13. UABCS - Museo de Historia Natural, Universidad Autónoma de Baja California Sur, La Paz, Baja California Sur, Mexico

14. USNM - National Museum of Natural History, Smithsonian Institution, Washington, DC, USA

15. ZLV - Université Catholique de Louvain, Musée de zoologie, Louvain-la-Neuve, Belgium

16. ZMA - Zoölogisch Museum Amsterdam, the Netherlands (collections now at NNML)

\subsection{Anatomical terminology}

Terminology for cranial anatomy follows Mead and Fordyce (2009) and, for cranial sinuses and the presphenoid and cribriform plate, Fraser and Purves (1960) and Ichishima (2016), respectively.
3 Systematic palaeontology

Order Cetacea Brisson, 1762

Pelagiceti Uhen, 2008

Neoceti Fordyce and de Muizon, 2001

Suborder Odontoceti Flower, 1867

Infraorder Delphinida de Muizon, 1988a

Superfamily Delphinoidea Gray, 1821

Family Delphinidae Gray, 1821

Genus Pliodelphis gen. nov.

urn:1sid:zoobank.org:act:

283002AE-779E-4BBA9E1F-C0561ADC7EC8

\section{Type species}

Pliodelphis doelensis sp. nov., herein designated.

\section{Etymology}

Plio from Pliocene and delphis from the Latin name for dolphin.

\section{Diagnosis}

Same as for the only included species.

Pliodelphis doelensis sp. nov.

urn:Isid:zoobank.org:act:

F62423D8-C845-4C32AB4F-BD7E5EEAEB10 (Figs. 2-4)

\section{Etymology}

From Doel, the Flemish village located on the left bank of the Scheldt just north of the Deurganck Dock, the type locality.

\section{Holotype}

Partial skull IRSNB M.2330 lacking the distal part of the rostrum, some portions of the facial region, and most of the lateral parts of the basicranium.

\section{Type locality}

The specimen IRSNB M.2330 was discovered in December 2000 in the Antwerp harbour (Belgium, southern margin of the North Sea basin), more precisely in the Deurganck Dock, Doel (Fig. 1), during the excavation of this large dock. Geographic coordinates: $51^{\circ} 17^{\prime} 30^{\prime \prime} \mathrm{N}, 4^{\circ} 15^{\prime} 36^{\prime \prime} \mathrm{E}$. 


\section{Type horizon and age}

The specimen was found in situ in layers of the Kattendijk Formation, cropping out for more than $2 \mathrm{~m}$ along the walls of the Deurganck Dock. The Kattendijk Formation has been dated based on dinoflagellate cysts sampled in the Deurganck Dock and nearby sections (Verrebroek Dock, $2 \mathrm{~km} \mathrm{SWW}$; Tunnel-Canal Dock, $3.5 \mathrm{~km}$ NEE) from a 5 to $4.4 \mathrm{Ma}$ time interval (Zanclean, early Pliocene; Louwye et al., 2004; De Schepper et al., 2009). This unit represents a neritic environment, with some open-marine influence, deposited under a warm to temperate climate (De Schepper et al., 2009).

\section{Diagnosis}

This small size delphinid differs from other extinct and extant members of the family based on the following unique combination of characters: dorsal exposure of maxilla on rostrum being significantly narrower than dorsal exposure of premaxilla at short distance anterior to antorbital notch; maximum opening of mesorostral groove being located approximately at level of antorbital notches; transversely wide and anteroposteriorly long dorsal exposure of presphenoid anterior to bony nares, reaching anterior to level of antorbital notches; all dorsal infraorbital foramina being located posterior to level of premaxillary foramina; anteromedial sulcus being proportionally short, ending at a short distance anterior to antorbital notch; lateral margin of right premaxilla markedly and regularly convex on the neurocranium; and left premaxilla ending posteriorly before level of anterior margin of corresponding nasal, not contacting the latter (see detailed comparison with other delphinids below).

\section{Description}

General features: this small skull (preorbital width and neurocranium length estimated at 140 and $174 \mathrm{~mm}$, respectively; Table 1) is incomplete, only preserving (1) the proximal part of the rostrum, (2) the maxillae and part of the premaxillae, frontals, presphenoid, and cribriform plate in the facial area, (3) part of the supraoccipital and probably interparietal and most of the exoccipitals, including the occipital condyles, along the posterior part of the braincase, and (4) part of the palatines and vomer on the palate (Figs. 24). The preserved cross section of the rostrum is transversely wider than dorsoventrally high. Based on the width of the rostrum at its base and the direction of its lateral, dorsal, and ventral margins, we estimate by comparison with more complete delphinid crania that the rostrum of IRSNB M.2330 was narrow and relatively elongated, with premaxillae occupying most of the dorsal surface. The bony nares are proportionally wide (see below). In lateral view, the preserved ventrolateralmost portion of the occipital shield indicates that the temporal fossa did not reach much higher dorsally than the orbit. The vertex of the skull is only moderately elevated, with a
Table 1. Skull measurements (in $\mathrm{mm}$ ) for Pliodelphis doelensis IRSNB M.2330 (holotype). The e signifies estimate, and + signifies incomplete.

\begin{tabular}{|c|c|}
\hline Maximum length of skull as preserved & e291 \\
\hline $\begin{array}{l}\text { Horizontal distance from posterior surface } \\
\text { of condyles to antorbital notch }\end{array}$ & e174 \\
\hline Maximum opening of mesorostral groove & 12 \\
\hline Width of rostrum at base & 95 \\
\hline Width of premaxillae at rostrum base & 55 \\
\hline Length of presphenoid anterior to bony nares & +53 \\
\hline $\begin{array}{l}\text { Distance between right and left premaxillary } \\
\text { foramina }\end{array}$ & 33 \\
\hline Preorbital width & +138 \\
\hline Width of bony nares & 54 \\
\hline $\begin{array}{l}\text { Minimum distance between maxillae anterior } \\
\text { to bony nares }\end{array}$ & 10 \\
\hline $\begin{array}{l}\text { Maximum width of right premaxilla (at anterior } \\
\text { margin of bony nares, including the medial } \\
\text { corner made by the maxilla) }\end{array}$ & $\mathrm{e} 35.5$ \\
\hline $\begin{array}{l}\text { Maximum width of left premaxilla (at anterior } \\
\text { margin of bony nares, including the medial corner } \\
\text { made by the maxilla) }\end{array}$ & $\mathrm{e} 30.5$ \\
\hline Maximum width of premaxillae & e81 \\
\hline Width across occipital condyles & 88 \\
\hline Width of foramen magnum & 36 \\
\hline Width of right occipital condyle & 31 \\
\hline Height of right occipital condyle & 50 \\
\hline $\begin{array}{l}\text { Maximum width of trough between maxillae } \\
\text { on the palate }\end{array}$ & 5.5 \\
\hline
\end{tabular}

gradual posterodorsal rise of the maxillae and premaxillae. In posterior view the occipital condyles are located low and the posterolaterally swollen aspect of the occipital shield indicates inflated brain hemispheres.

Ontogenetic stage: because no postcranial remains and teeth were preserved, we first base our assessment of the ontogenetic stage of IRSNB M.2330 on the degree of fusion of cranial bones. Only the preserved part of the exoccipitaloccipital suture and part of the palatine-maxilla suture display complete obliteration of the suture line; for part of the premaxilla-maxilla, palatine-maxilla, maxilla-frontal, and frontal-cribriform plate sutures, bones are firmly attached but with suture lines remaining visible; bones were not (or only loosely) attached along the jugal-maxilla, lacrimal-maxilla, part of premaxilla-maxilla, part of maxilla-frontal, interfrontal, nasal-frontal, frontal-supraoccipital (or interparietal), 
and palatine-vomer sutures. Altogether, these features suggest that this individual was not a neonate, showing for example some degree of fusion between the maxilla and premaxilla, but it was most likely not sexually mature, lacking for example an advanced fusion of the suture between frontal and interparietal and between nasal and frontal (see Perrin, 1975; Mead and Fordyce, 2009; Galatius, 2010; Chen et al., 2011), a hypothesis that is further supported by the relatively low degree of retrograde cranial telescoping (sensu Churchill et al., 2018), as indicated by the anteroposteriorly long supraoccipital and interparietal exposure in dorsal view compared to adults of many extant delphinid species (Perrin, 1975; Arnold and Heinsohn, 1996; this work). Strong differences in the timing of the fusion of cranial sutures observed between extant delphinid species, in relation to heterochronic processes (Galatius, 2010), prevent us from providing a more precise age estimate. Still, the development of a relatively long presphenoid, reaching anterior to the level of the antorbital notches, suggests that this immature individual was closer to subadult than to neonate (see Ichishima, 2016).

Premaxilla: at their preserved anterior end, the premaxillae were distinctly wider than the maxillae in dorsal view (Fig. 2), displaying a wide and flat dorsal surface, sloping ventrolaterally, and made of compact bone (porcelanous part). Anteriorly the two premaxillae nearly contact each other dorsomedially; they diverge markedly posterolaterally, broadly opening the mesorostral groove until a maximum transverse width at the anteroposterior level of the antorbital notches. This divergence is associated with a clear transverse narrowing of each premaxilla until the anterior tip of the prenarial triangle. Laterally defined by a shallow anteromedial sulcus, the prenarial triangle is anteroposteriorly short, slightly transversely concave with a raised medial edge, and low compared to the more compact lateral part of the bone. Right and left premaxillary foramina are small, with a transverse diameter of 3-4 $\mathrm{mm}$, and located just posterior to the level of the antorbital notches. Posterior to the premaxillary foramina, only part of the medial portion of the premaxillae is preserved, as well as a lateral-most portion of the right premaxilla. Such an incomplete preservation does not allow for a precise assessment of the extent of the premaxilla above the maxilla along the anterior margin of the bony nares; however, the height and width of the presphenoid in this area (see below) indicate that right and left premaxillae and maxillae remained distant from each other at this level. More posteriorly, the outline of each premaxilla is estimated based on the clear suture marks observed on the underlying ascending process of the maxilla. We reconstruct a considerably transversely wider right ascending process of the premaxilla, being about 2 times wider than the left at mid-length of the bony nares. The right ascending process is also much longer posteriorly, nearly reaching the level of the posterior margin of the fossa for the nasal on the frontal, whereas the left premaxilla originally ended before the level of the posterodorsal margin of the cribriform plate. The lateral margin of the right premaxilla is strongly laterally convex; this margin is not as bowed on the left side where it lied on a portion of the maxilla that is more dorsally raised relative to the lateral part of the maxilla, as compared to the right side.

Maxilla: in dorsal view, the maxilla was originally only exposed as a narrow stripe lateral to the wide premaxilla at the preserved anterior end of the rostrum (Fig. 2). Its dorsal exposure increases gradually towards the level of the antorbital notch. At rostrum base the maxilla is dorsally lower than the porcelanous part of the premaxilla (Fig. 3). All dorsal infraorbital foramina are located posterior to the antorbital notches and even posterior to the premaxillary foramina: five foramina are counted on the right maxilla, including two medium size anterior foramina, one along the premaxilla-maxilla suture and one posterolateral, two small size foramina, and one large size foramen posterolaterally at a level about one third of the length of the bony nares; four foramina are counted on the left maxilla, including two medium size anterior foramina as on the right side, only one small foramen, and a larger posterolateral foramen. Based on the better-preserved right antorbital process of the maxilla, the antorbital notch is $U$ shaped and broadly anterolaterally open. The loss of the frontal, lacrimal, and jugal in this region does not allow for an assessment of the anteroposterior depth of the antorbital notch. In the supraorbital region the maxilla slopes moderately ventrolaterally and its preserved dorsal surface is devoid of any maxillary crest. More complete than the left, the right ascending process of the maxilla did not originally fully cover the frontal posteriorly. This region of the maxilla is transversely and anteroposteriorly convex, reflecting some degree of inflation of the brain cavity.

In ventral view the two maxillae nearly contact each other anteriorly (Fig. 4a); the medial margins diverge posterolaterally to form a spindle-shaped trough with a maximum width of $5.5 \mathrm{~mm}$ at about $35 \mathrm{~mm}$ from the level of the antorbital notches, originally housing the vomer (lost in this area). We estimate that the alveolar groove started about $30 \mathrm{~mm}$ anterior to the antorbital notch; however, the spongy aspect of the maxilla in this region suggests that wear removed part of the superficial bone, and no individual tooth alveolus could be detected. Posteromedially the maxillae are ventrally covered by the palatines; although only the posterolateral-most part of the maxilla-palatine suture could be detected, the position of the greater palatine foramen provides a clue for the anteromedial extent of the suture. Posteromedial to the antorbital notch, and partly covering the maxilla-palatine suture, a smooth and slightly transversely concave surface suggests that the anterior sinus was present but short, not extending for more than $20 \mathrm{~mm}$ anterior to the level of the antorbital notch. Between this shallow fossa for the anterior sinus and the antorbital notch, the deep, triangular zygomatic recess marks the suture with the lost jugal. Posterior to the recess, the loss of both the lacrimal and frontal prevent us from evaluating the outline of the orbit and ventral infraorbital foramen. 

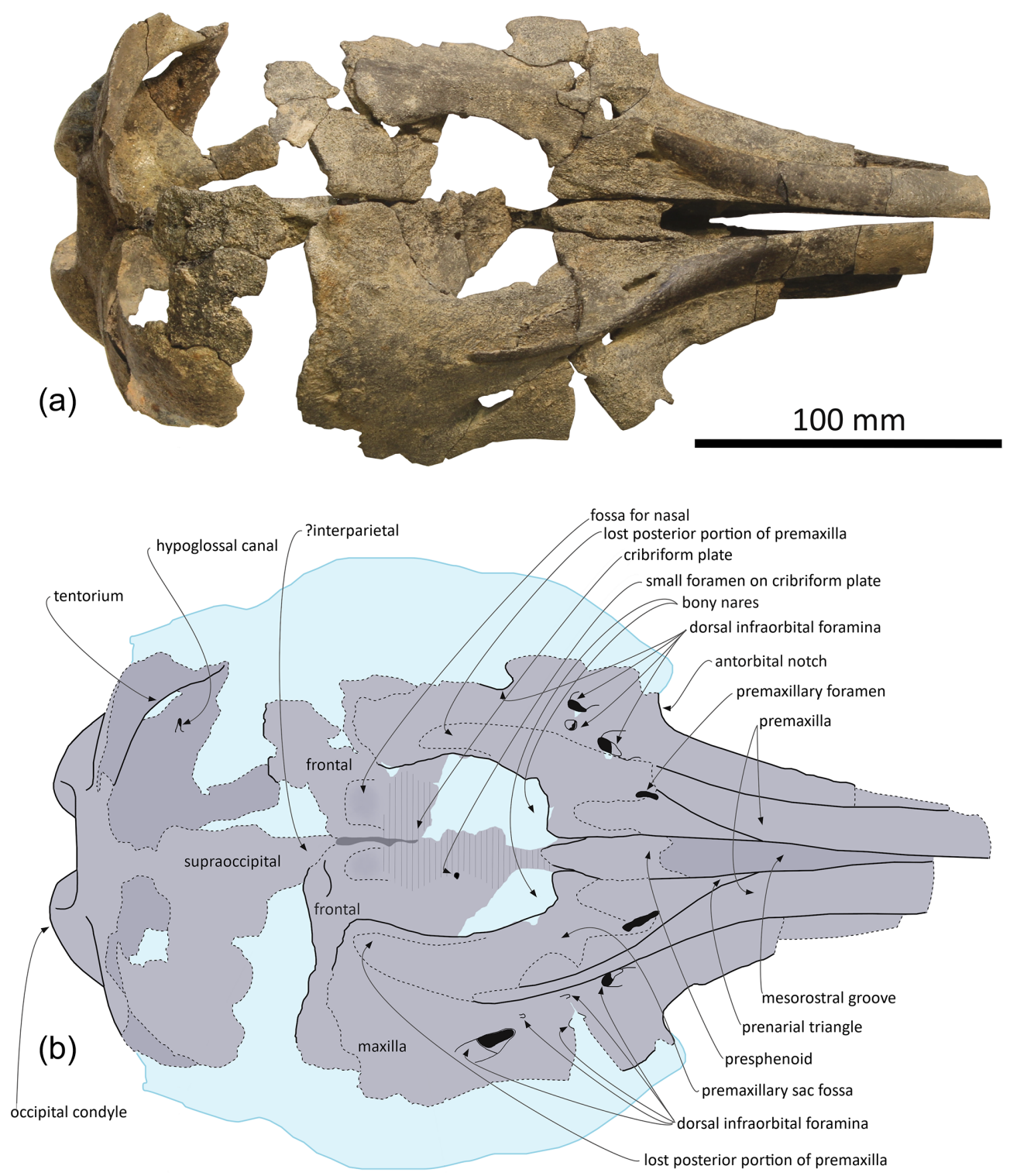

Figure 2. Skull of Pliodelphis doelensis gen. nov., sp. nov. IRSNB M.2330 (holotype): (a) dorsal view; (b) interpretive line drawing. Dotted lines correspond to incomplete elements, reconstructed posterior part of the premaxillae, and shallow fossae for the lost nasals.

Presphenoid and cribriform plate: broadly dorsally exposed between the maxillae and premaxillae from the anterior margin of the bony nares, the tubular presphenoid extends for at least $53 \mathrm{~mm}$ anteriorly beyond the level of the antorbital notches (Fig. 2). It is anteriorly made of cancellous bone, partly lost in its central portion and suggesting that it may have been originally anteriorly longer. Most of the dorsal part of the nasal septum has been eroded, as well as part of the anterodorsal surface of the cribriform plate. The latter is broad, with an arched posterodorsal margin reaching dorsally lower than the nasals and frontals (Fig. 4c), and there is no indication for a sagittal keel extending the nasal septum until the suture with the frontal. A small foramen pierces the cribriform plate at about one third of its height, slightly lateral (on the right side) to the sagittal plane, possibly corresponding to a vestigial passage for a branch of the olfactory nerve (see Mead and Fordyce, 2009; Godfrey, 2013).

Frontal: frontals are only partly preserved posterior to the bony nares and below and beyond the posterior portion of the ascending processes of the maxillae. Between the maxillae, the right frontal is transversely wider than the left ( 22 and $17.5 \mathrm{~mm}$, respectively). Just dorsal to the cribriform plate, a shallow fossa excavates each frontal, most likely corresponding to part of the area of contact with the nasal (Fig. 2). Because the surface of the bone is somewhat damaged on each side, we cannot estimate the total extent of the original cover of each frontal by the corresponding nasal. Nevertheless, a marked elevation of the right frontal posterior to the fossa 
(a)

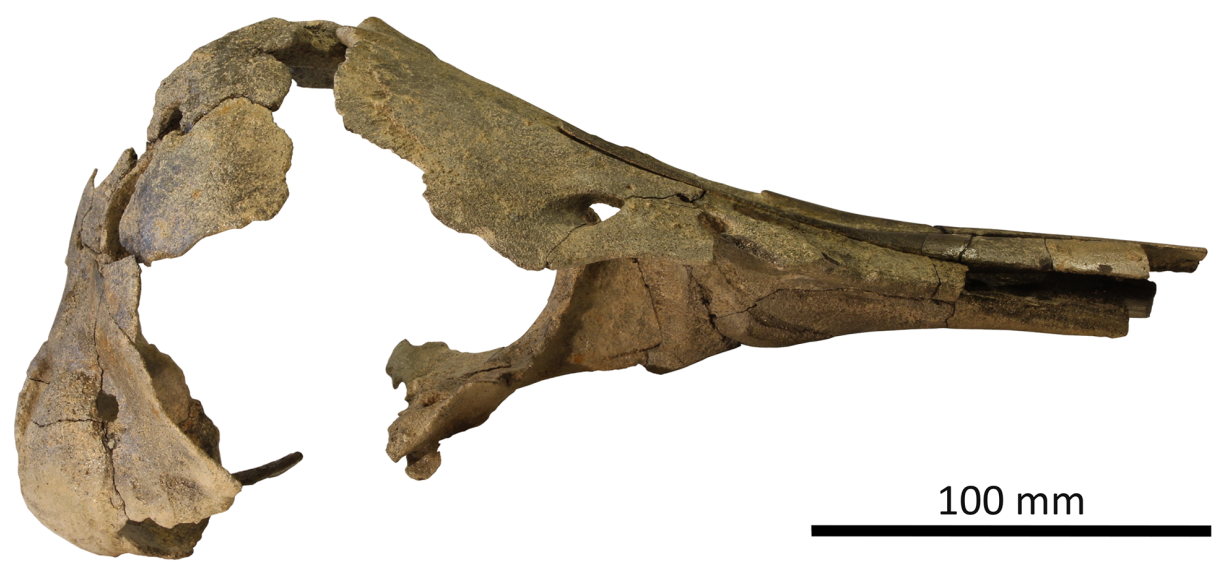

(b)

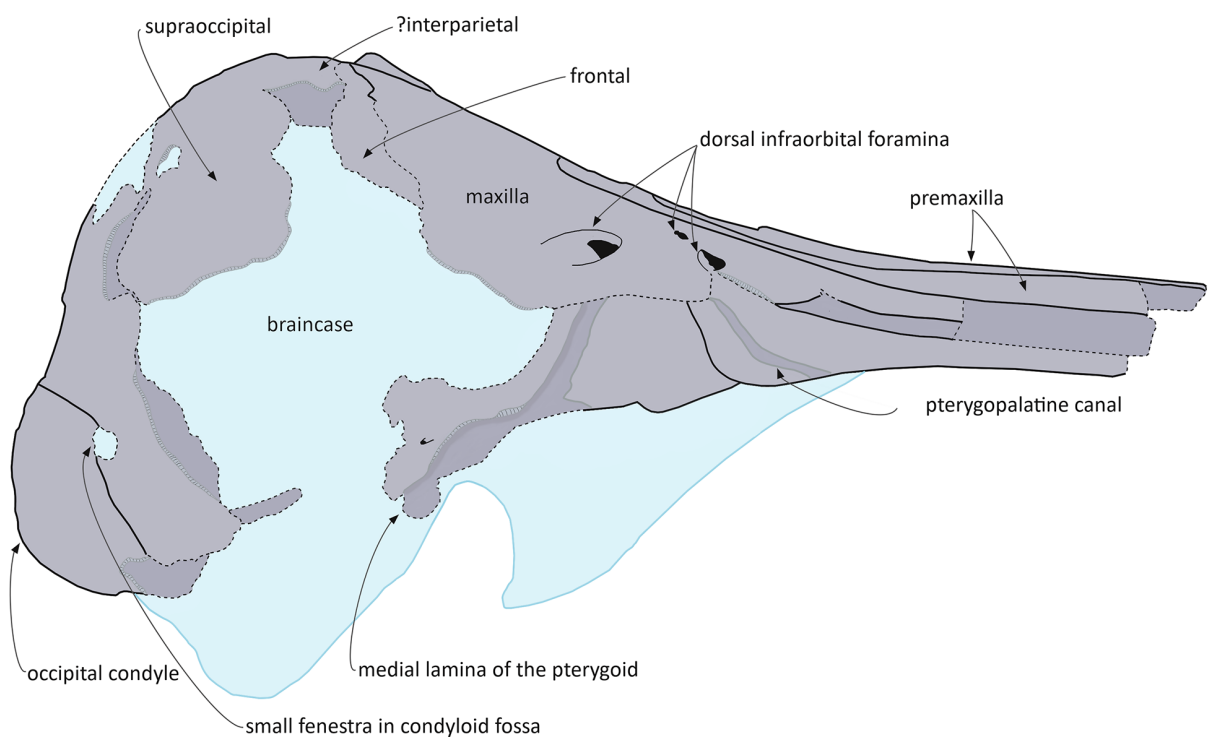

Figure 3. Skull of Pliodelphis doelensis gen. nov., sp. nov. IRSNB M.2330 (holotype): (a) right lateral view and (b) interpretive line drawing. Dotted lines correspond to incomplete elements.

for the nasal indicates that the frontal was exposed dorsally between the nasal and the supraoccipital (or interparietal).

Supraoccipital and interparietal: the anteromedial projection of the occipital shield between the frontals is interpreted as related to the early ontogenetic stage of this individual, and this anteromedial-most area may correspond to the interparietal (see for example Arnold and Heinsohn, 1996, fig. 15; Mead and Fordyce, 2009, fig. 6a; Fig. 2). The few places where the external surface of the supraoccipital is preserved reveal a convex, inflated bone. Above the foramen magnum the supraoccipital displays a broad sagittal groove.

Palatal region: the palatine is preserved in the region anterior to the choanae. The sutures with the maxillae can only be detected posterolaterally, especially on the right side (Fig. 4a). In ventral view, each palatine displays a flat medial surface that faces ventrally and slightly anteriorly. Laterally, the surface turns abruptly dorsally, towards the transversely concave region of the palatine and maxilla including the shallow fossa for the anterior sinus (see above). The ventrolaterally facing part of the surface of each palatine is obliquely crossed by a narrow sulcus, the pterygopalatine canal, originally partly covered by the pterygoid and reaching the major palatine foramen. Posteromedial to this canal, a shallow fossa extends for about $12 \mathrm{~mm}$ anterior to each choana, corresponding to a short anterior portion of the pterygoid sinus fossa, ending anteriorly before the level of the antorbital notches.

The main parts of the pterygoids are lost. The only exception could be a small portion of the right medial lamina located along the posterolateral part of the vomer (Figs. 3, $4 a)$.

No portion of the vomer in the mesorostral groove is preserved; this bone can only be seen in ventral view, where the ventral tubercle and nasal septum separate the choanae 


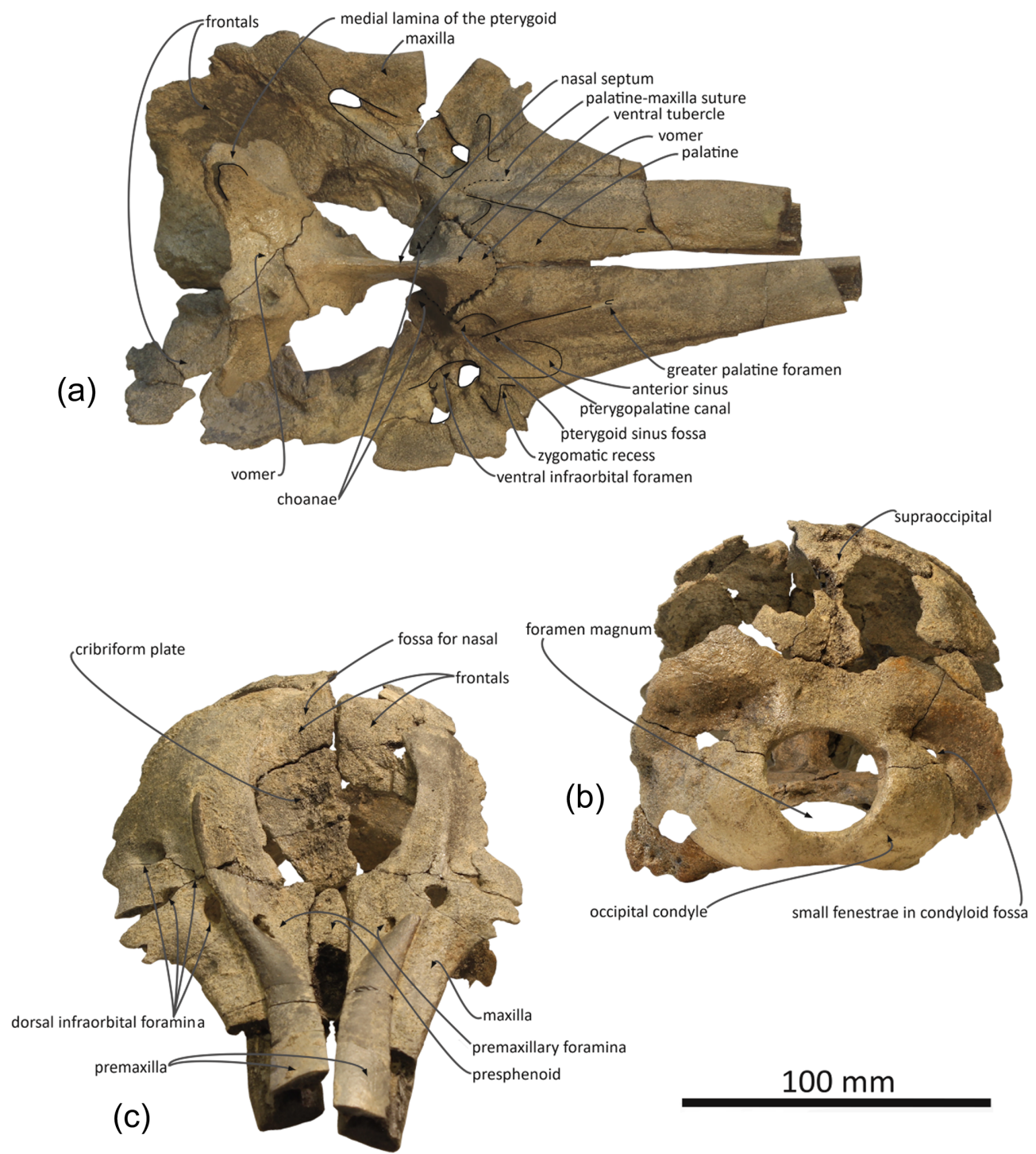

Figure 4. Skull of Pliodelphis doelensis gen. nov., sp. nov. IRSNB M.2330 (holotype): (a) ventral view, lacking the basicranium, (b) posterior view, and (c) anterodorsal view.

(Fig. 4a). Posteriorly, the bone appears to be preserved until the sphenoidal incisure.

Occipital region: compared to the other cranial dimensions the subcircular foramen magnum is large (Fig. 4b). The occipital condyles barely protrude posteriorly, without any condylar neck, and they are dorsolaterally margined by deep and broad dorsal condyloid fossae. Inside each fossa is a small fenestra that was only slightly enlarged by postmortem damage on the right side. Similar fenestrae are observed in some extant delphinids, for example in all age classes of Sotalia spp. (see Fettuccia et al., 2009). The dorsal condyloid fossa is followed dorsolaterally by a marked swelling of the exoccipital's posterior surface. Inside the brain cavity, this swelling corresponds to the region just above the tentorium. Below the latter, the left hypoglossal canal is visible on the floor of the concavity for the lobes of the cerebellum, posteromedial to the partly preserved jugular notch.

The basioccipital is only partly preserved on the floor of the basioccipital basin, not providing any relevant anatomical feature.

\section{Comparison}

For the comparison of the immature individual skull of Pliodelphis doelensis IRSNB M.2330, we mostly used crania of adult and subadult specimens (Figs. 5, 6). However, we took account of ontogenetic changes in extant delphinids for most characters discussed here using our own observations and data from the literature (e.g. Perrin, 1975; Arnold and Heinsohn, 1996; Mead and Fordyce, 2009; Chen et al., 2011). 


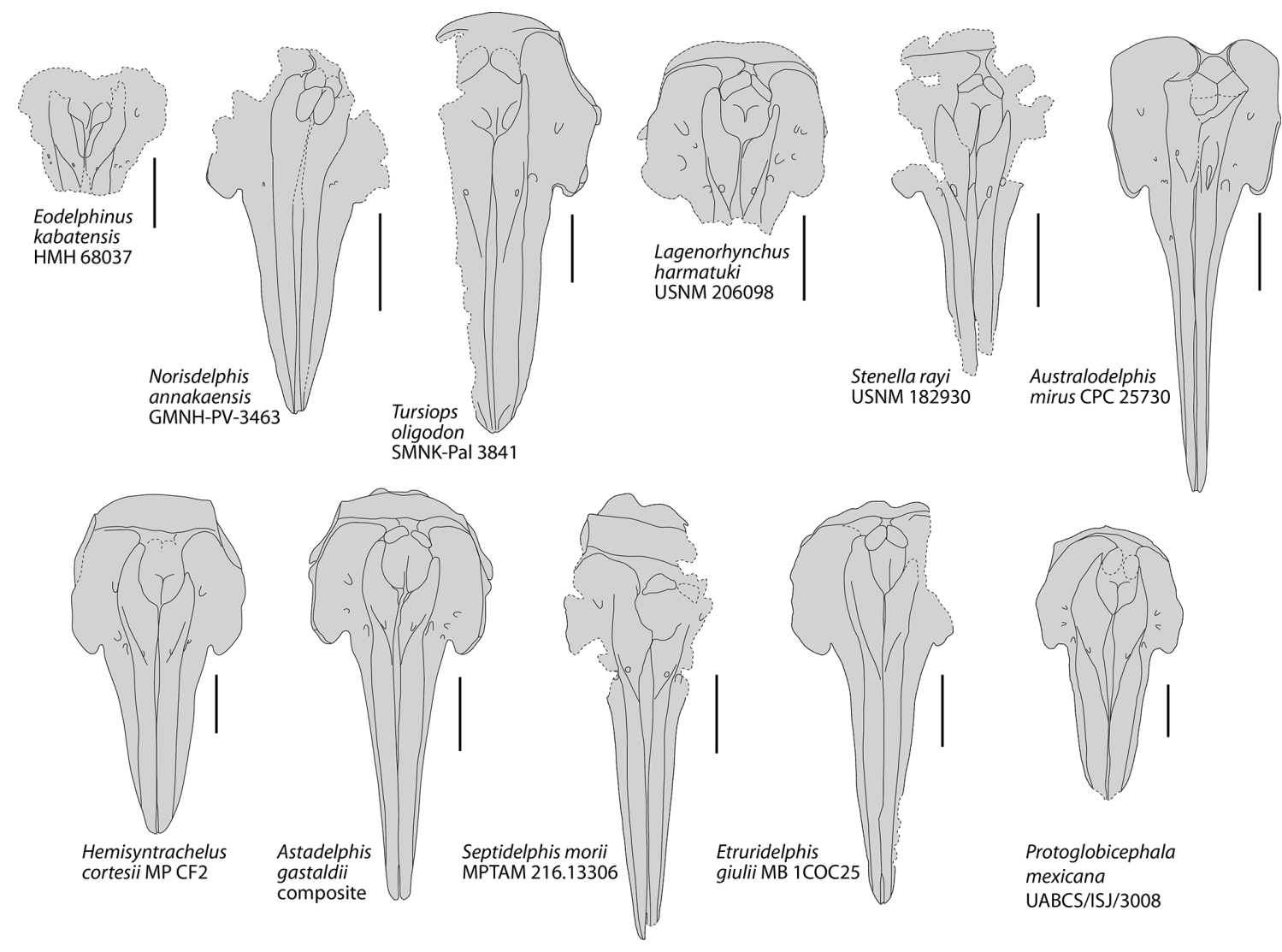

Figure 5. Schematic dorsal view of the skull in a series of extinct delphinids from the late Miocene and Plio-Pleistocene. Based on photos and drawings in Bianucci (1996, 2013); Fordyce et al. (2002); Aguirre-Fernández et al. (2009); Murakami et al. (2014), Kimura and Hasegawa (2020), and photos kindly provided by Mark Bosselaers (for Tursiops oligodon) and Giovanni Bianucci (for Lagenorhynchus harmatuki and Stenella rayi). Dotted lines correspond to incomplete elements. All crania scaled at same width of premaxillary sac fossae. Scale bars $=100 \mathrm{~mm}$.

Family assignment: Pliodelphis doelensis is referred to the family Delphinidae based on the following combination of characters observed in the holotype (see de Muizon, 1988a; Bianucci, 2013):

1. strong asymmetry of the premaxillae around the bony nares, with the right ascending process being transversely much wider (about 2 times at mid-length of the bony nares) and considerably posteriorly longer than the left;

2. transversely wide and plate-like posterodorsal portion of the cribriform plate with arched posterodorsal margin.

Among crown delphinoids, phocoenids (porpoises) and the extinct albireonids display greatly elevated frontals at the vertex (the so-called frontal boss) and premaxillary eminences that are absent in P. doelensis; part of the phocoenids are also characterized by anteroposteriorly shortened and transversely narrow ascending processes of the premaxillae that display a lesser degree of asymmetry than in P. doelensis (e.g. de Muizon, 1988a, b; Ichishima and Kimura, 2005;
Barnes, 2008; Colpaert et al., 2015; Laeta et al., 2021). Monodontids (narwhal, beluga, and relatives) share a broad medial exposure of the maxilla along the anterolateral wall of the bony nares and a posterior accessory foramen located at the posterior end of the premaxilla (e.g. Vélez-Juarbe and Pyenson, 2012; Ichishima et al., 2019), two features that are absent in P. doelensis. Phocoenids and monodontids further display a transversely narrower cribriform plate compared to P. doelensis and other delphinids. With its unique walrus-like skull morphology, the extinct Odobenocetops (proposed to represent a highly specialized relative of monodontids; e.g. de Muizon and Domning, 2002) differs markedly from $P$. doelensis. Finally, additional similarities between $P$. doelensis and part of the delphinids (extinct and extant) at the level of the dorsal infraorbital foramina, proportions of the dorsal exposure of the maxilla and premaxilla at rostrum base, and the extent of the dorsal opening of the mesorostral groove (see below) further support an attribution of the new species to the family Delphinidae.

Comparison with other small to medium size extinct and extant delphinids: among extant delphinids, this small del- 

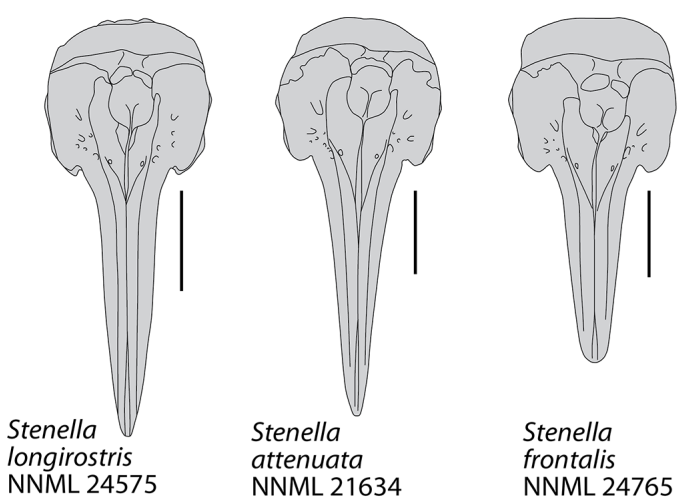
NNML 24765
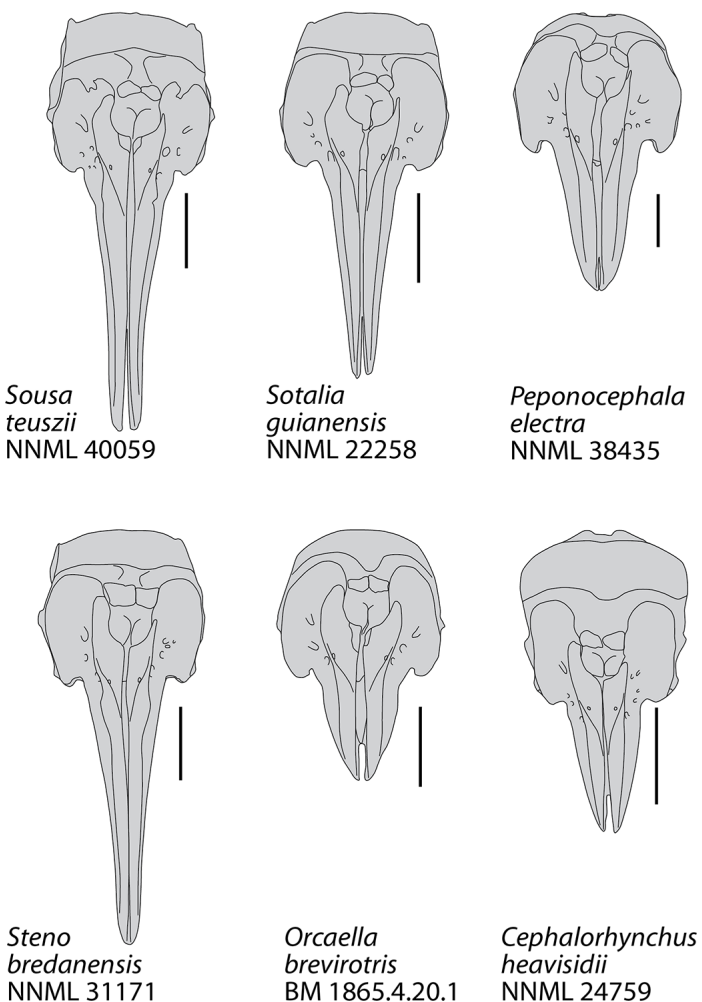

Orcaella brevirotris BM 1865.4.20.1

Cephalorhynchus heavisidii NNML 24759
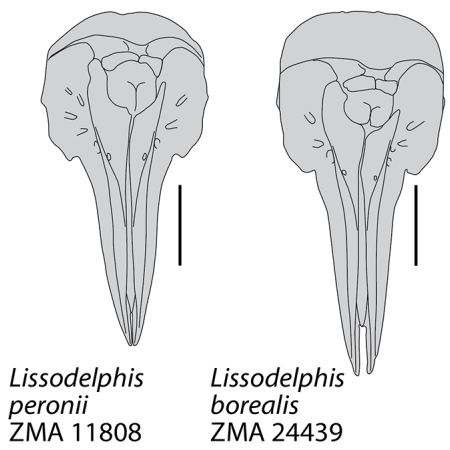

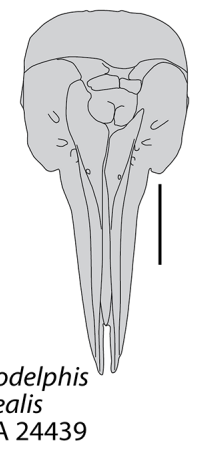

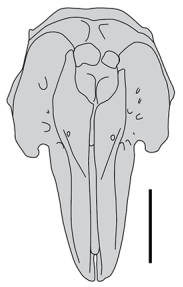
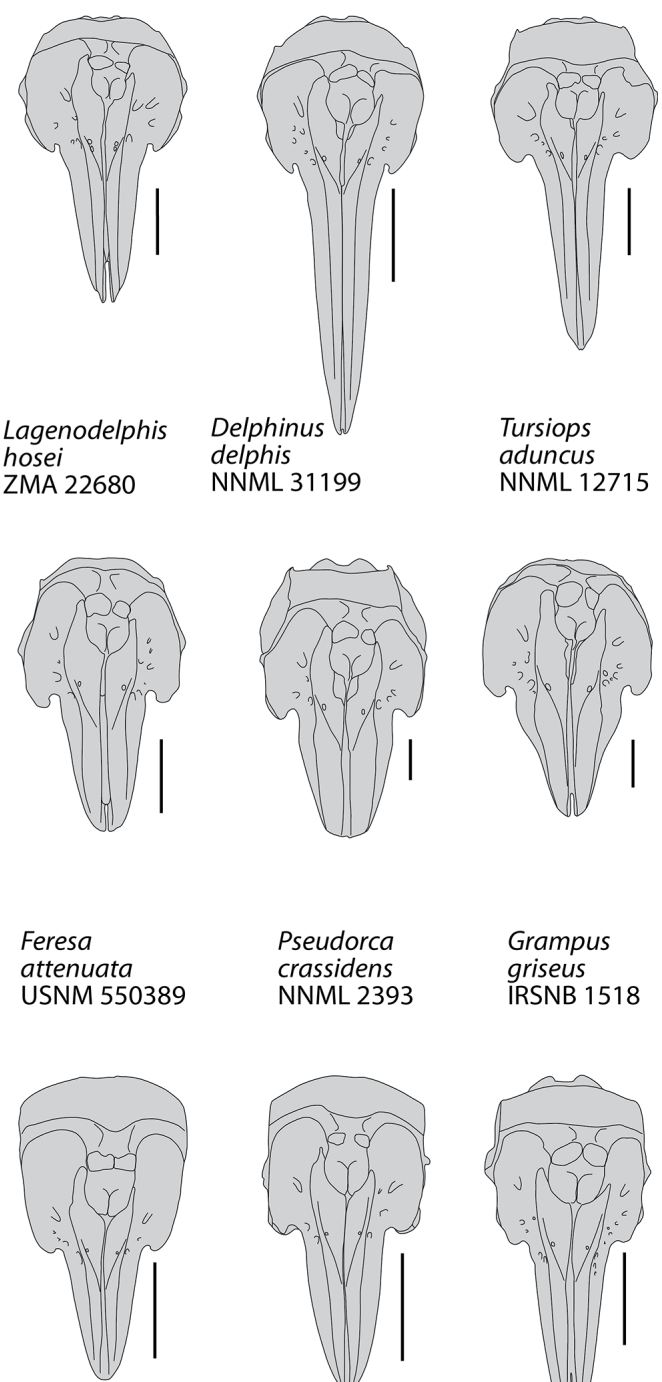

delphis

NNML 31199

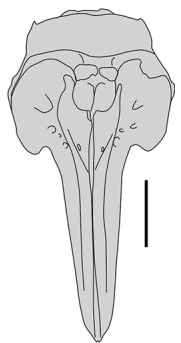

Tursiops

aduncus

NNML 12715

Grampus

griseus

IRSNB 1518

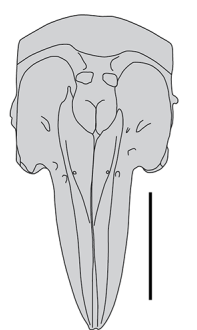

Cephalorhynchus hectori

ZMA 15210

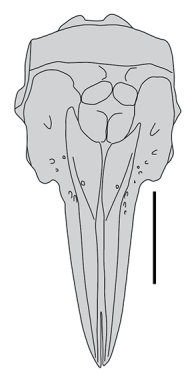

Sagmatias obscurus NNML 24764

Figure 6. Schematic dorsal view of the skull in a series of extant small to medium size delphinids. Based on original photos (in large part kindly provided by Giovanni Bianucci) and Arnold and Heinsohn (1996, for Orcaella brevirostris). All crania scaled at same bizygomatic width. Scale bars $=100 \mathrm{~mm}$. 
phinid has a rostrum base width in the range of Delphinus delphis and Stenella attenuata, larger than in Sotalia spp. and Stenella longirostris, and smaller than in Lissodelphis borealis and Sousa plumbea (e.g. Perrin, 1975; Ross, 1984; Alice Belluzzo and Olivier Lambert, personal observation, 2020; Table 1). Among extinct delphinids, the width at rostrum base is smaller than in Australodelphis mirus, Lagenorhynchus harmatuki, Norisdelphis annakaensis, Tursiops oligodon, to a lesser extent Stenella rayi, and all species from the Italian Pliocene except Septidelphis morii; however, the latter has a greater width across occipital condyles (Fordyce et al., 2002; Bianucci, 2013; Kimura and Hasegawa, 2020; Alice Belluzzo and Olivier Lambert, personal observation, 2020). The bony nares are proportionally large, with a ratio between their maximum width and the width at rostrum base equal to 0.57 , which is higher than in many extinct and extant small to medium size delphinids.

In Pliodelphis doelensis IRSNB M.2330 the dorsal exposure of the maxilla on the rostrum is significantly narrower than the dorsal exposure of the premaxilla from a short distance $(40 \mathrm{~mm}$ in this specimen) anterior to the antorbital notch in a way similar to the extinct Astadelphis gastaldii, A. mirus, Etruridelphis giulii, S. morii, S. rayi, and Protoglobicephala mexicana (Bianucci, 1996, 2013; Fordyce et al., 2002; Whitmore and Kaltenbach, 2008; Aguirre-Fernández et al., 2009; Bianucci et al., 2009; Fig. 5) but differing from Hemisyntrachelus cortesii, $N$. annakaensis, and T. oligodon (Pilleri and Siber, 1989; Bianucci, 1996; Murakami et al., 2014), as well as most small to medium size extant delphinids except Sotalia, Sousa, and, to a lesser extent, Steno (as well as shorter-snouted forms like Feresa, Grampus, and Orcaella) (Fig. 6). Of note, based on more complete specimens, this character was quantified by Bianucci (2013) using a ratio between the width of premaxillae at rostrum midlength and the width of the rostrum at the same level. Further anterolateral widening of the premaxillae is observed in Globicephala macrorhynchus and the Plio-Pleistocene Platalearostrum hoekmani (Post and Kompanje, 2010).

In P. doelensis IRSNB M.2330 the maximum opening of the mesorostral groove is located approximately at the level of the antorbital notches, as in the extinct $P$. mexicana and S. morii, whereas it is more anterior in A. gastaldii, N. annakaensis, Stenella rayi, and T. oligodon, and the mesorostral groove is roughly dorsally closed in A. mirus, E. giulii, and $H$. cortesii (Fig. 5). The maximum opening is more anteriorly located in all extant small to medium size delphinids except Peponocephala electra, in which a wide opening extends more posteriorly (Fig. 6).

Partly related to the aforementioned character, IRSNB M.2330 displays a transversely wide and anteroposteriorly long dorsal exposure of the presphenoid anterior to the bony nares, reaching anterior to the level of the antorbital notches. This condition differs from all other extinct delphinids, in which the two premaxillae are closer to each other (often nearly contacting each other) at least in part of the region between the anterior margin of the bony nares and the level of the antorbital notches (Fig. 5). The difference may be less marked in $S$. rayi, displaying more widely separated premaxillae in this whole area, and $S$. morii, characterized by an abrupt anterior separation of the two premaxillae, but the presphenoid is not preserved (or much shorter) in the holotype of S. morii, and the dorsal surface of this bone descends more gradually anteroventrally in the holotype of $S$. rayi. This condition further differs from most extant small to medium size delphinids except Peponocephala, Sotalia, and, to a lesser extent, Orcaella (Fig. 6). Such a condition is also seen in the larger Globicephala (e.g. G. macrorhynchus IRSNB 1513). In at least some extant delphinid species, the anterior growth and dorsal exposure of the presphenoid are observed to increase with age (Perrin, 1975; Ichishima, 2016).

In IRSNB M.2330, all dorsal infraorbital foramina are posterior to the level of the premaxillary foramina, a condition that differs from A. gastaldii, A. mirus, E. morii, L. harmatuki, and $S$. rayi but not from Eodelphinus kabatensis and P. mexicana (Fig. 5); among extant delphinids this condition is only seen in a few taxa, including Globicephala and Peponocephala (Fig. 6).

The anteromedial sulcus is proportionally short in IRSNB M.2330, differing mostly from taxa with a relatively short and broad rostrum (e.g. Cephalorhynchus, Grampus, Lissodelphis, P. mexicana, and Sotalia).

The lateral margin of the right premaxilla is markedly and regularly convex on the neurocranium of IRSNB M.2330, differing from most extant delphinids except Feresa, Orcaella, Sotalia, and Sousa, and being more similar to the extinct A. gastaldii, E. giulii, H. cortesii, and P. mexicana (Figs. 5, 6).

We interpret the left premaxilla of IRSNB M.2330 as ending posteriorly before the level of the anterior margin of the corresponding nasal, not originally contacting the latter; this is a marked difference from the extinct A. mirus, $N$. annakaensis, T. oligodon, and possibly E. kabatensis (Fig. 5). A vast majority of extant delphinids similarly lack such a contact; only a few specimens display a limited premaxilla-nasal contact on the left side (e.g. Pseudorca crassidens NNML 2393) or a left premaxilla reaching posteriorly farther than the anterior margin of the corresponding nasal but lacking a contact (e.g. Lagenorhynchus albirostris NNML 16882) (Fig. 6).

IRSNB M.2330 further lacks all the highly unusual, ziphiid-like morphological features of the facial region seen in A. mirus (e.g. right premaxillary foramen located far posteriorly, enlarged left premaxillary foramen included in a deep depression, and strong posterodorsal elevation of the ascending processes of the premaxillae; Fordyce et al., 2002; Fig. 6). 
Table 2. Named delphinid species from the Neogene worldwide (modified from Bianucci, 2013).

\begin{tabular}{|c|c|c|c|c|c|}
\hline $\begin{array}{l}\text { Genus and } \\
\text { species }\end{array}$ & Region/country & Ocean/sea & Lithological unit & Geological age & References \\
\hline \multicolumn{6}{|l|}{ Late Miocene } \\
\hline Norisdelphis annakaensis & Gunma Prefecture, Japan & North-west Pacific & Haraichi Formation & $\begin{array}{l}\text { Tortonian (early } \\
\text { late Miocene) } \\
11.29-11.25 \mathrm{Ma}\end{array}$ & $\begin{array}{l}\text { Kimura and } \\
\text { Hasegawa (2020) }\end{array}$ \\
\hline Eodelphinus kabatensis & Hokkaido, Japan & North-west Pacific & Mashike Formation & $\begin{array}{l}\text { Tortonian (early } \\
\text { late Miocene) } \\
13.0-8.5 \mathrm{Ma}\end{array}$ & Murakami et al. (2014) \\
\hline Tursiops oligodon & Sacaco basin, Peru & South-east Pacific & $\begin{array}{l}\text { Pisco Formation, } \\
\text { Sud-Sacaco level }\end{array}$ & $\begin{array}{l}\text { Late Messinian } \\
\text { (latest Miocene) } \\
\text { ca. } 7.3-5.93 \mathrm{Ma}\end{array}$ & $\begin{array}{l}\text { Pilleri and } \\
\text { Siber (1989), } \\
\text { Ehret et al. (2012) }\end{array}$ \\
\hline \multicolumn{6}{|l|}{ Pliocene-Early Pleistocene } \\
\hline Australodelphis mirus & Vestfold Hills, Antarctica & Southern Ocean & Sørsdal Formation & $\begin{array}{l}\text { Zanclean (early Pliocene) } \\
\text { ca. } 4.5-4.1 \mathrm{Ma}\end{array}$ & Fordyce et al. (2002) \\
\hline Lagenorhynchus harmatuki & North Carolina, USA & North Atlantic & Yorktown Formation & $\begin{array}{l}\text { Zanclean (early Pliocene) } \\
4.9-3.9 \mathrm{Ma}\end{array}$ & $\begin{array}{l}\text { Whitmore and } \\
\text { Kaltenback (2008), } \\
\text { Marx and } \\
\text { Fordyce (2015) }\end{array}$ \\
\hline Stenella rayi & North Carolina, USA & North Atlantic & Yorktown Formation & $\begin{array}{l}\text { Zanclean (early Pliocene) } \\
4.9-3.9 \mathrm{Ma}\end{array}$ & $\begin{array}{l}\text { Whitmore and } \\
\text { Kaltenback (2008), } \\
\text { Marx and } \\
\text { Fordyce (2015) }\end{array}$ \\
\hline Pliodelphis doelensis & Antwerp area, Belgium & North Sea & Kattendijk Formation & $\begin{array}{l}\text { Zanclean (early Pliocene) } \\
5.0-4.4 \mathrm{Ma}\end{array}$ & This work \\
\hline Tursiops osennae & Tuscany, Italy & Mediterranean & Unnamed unit & $\begin{array}{l}\text { Zanclean-Piacenzian } \\
\text { (Pliocene) }\end{array}$ & Bianucci (1996) \\
\hline Etruridelphis giulii & Tuscany, Italy & Mediterranean & Unnamed unit & $\begin{array}{l}\text { Zanclean-Piacenzian } \\
\text { (Pliocene) } \\
4.0-2.8 \mathrm{Ma}\end{array}$ & $\begin{array}{l}\text { Bianucci et al. (2009), } \\
\text { Bianucci (2013) }\end{array}$ \\
\hline Hemisyntrachelus cortesii & $\begin{array}{l}\text { Emilia Romagna, Pied- } \\
\text { mont, and Tuscany, Italy }\end{array}$ & Mediterranean & Various units & $\begin{array}{l}\text { Zanclean-Piacenzian } \\
\text { (Pliocene) }\end{array}$ & Bianucci (1996) \\
\hline Orcinus citoniensis & Tuscany, Italy & Mediterranean & Unnamed unit & $\begin{array}{l}\text { Zanclean-Piacenzian } \\
\text { (Pliocene) }\end{array}$ & Bianucci (1996) \\
\hline Septidelphis morii & Piedmont, Italy & Mediterranean & Sabbie di Asti & $\begin{array}{l}\text { Late Zanclean-early } \\
\text { Piacenzian (Pliocene) } \\
\text { 3.81-3.19 Ma }\end{array}$ & Bianucci (2013) \\
\hline Astadelphis gastaldii & Piedmont, Italy & Mediterranean & Sabbie di Asti & $\begin{array}{l}\text { Late Zanclean-early } \\
\text { Piacenzian (Pliocene) } \\
3.81-3.19 \mathrm{Ma}\end{array}$ & Bianucci $(1996,2013)$ \\
\hline Protoglobicephala mexicana & $\begin{array}{l}\text { Baja California Sur, } \\
\text { Mexico }\end{array}$ & North-east Pacific & Unnamed unit & $\begin{array}{l}\text { Piacenzian (late Pliocene) } \\
\text { ca. } 3.0-2.0 \mathrm{Ma}\end{array}$ & $\begin{array}{l}\text { Aguirre-Fernández } \\
\text { et al. (2009) }\end{array}$ \\
\hline Platalearostrum hoekmani & $\begin{array}{l}\text { North Sea (trawling), } \\
\text { the Netherlands }\end{array}$ & North Sea & Unnamed unit & $\begin{array}{l}\text { Piacenzian-Gelasian (late } \\
\text { Pliocene-Early } \\
\text { Pleistocene) }\end{array}$ & $\begin{array}{l}\text { Post and } \\
\text { Kompanje (2010) }\end{array}$ \\
\hline Arimidelphis sorbinii & Emilia Romagna, Italy & Mediterranean & Unnamed unit & $\begin{array}{l}\text { Piacenzian-Gelasian (late } \\
\text { Pliocene-Early } \\
\text { Pleistocene) } \\
3.1-2.2 \mathrm{Ma}\end{array}$ & Bianucci (2005) \\
\hline
\end{tabular}

\section{Discussion and conclusions}

Due to the fragmentary nature of the holotype IRSNB M.2330, we did not include Pliodelphis doelensis in a cladistic analysis. Indeed, only 3 characters (of a total of 14) could be coded for this specimen in the matrix of the analysis dedicated to delphinids by Bianucci (2013), and about 38 (of a total of 282) in the matrix of the odontocete analysis by Murakami et al. (2014) and Kimura and Hasegawa (2020), making any cladistic analysis poorly resolved, especially considering the high number of extant delphinid species (at least 37 in 17 genera; Committee on Taxonomy, 2020). 
Considering the lack of a consensus on the content and diagnostic cranial characters for the main delphinid subfamilies (e.g. de Muizon, 1988a; LeDuc et al., 1999; Bianucci, 2005, 2013; McGowen et al., 2009, 2020; Murakami et al., 2014; Kimura and Hasegawa, 2020) and, again, the fragmentary state of the holotype, P. doelensis could not be attributed to a given subfamily. Although the similarities noted with Orcaella, Peponocephala, Sotalia, and Sousa (see above) may indicate closer relationships with Globicephalinae and/or Delphininae, more complete specimens will be needed to further test the relationships of this new small delphinid species.

Though fragmentarily known, Pliodelphis doelensis is the first delphinid named from the early Pliocene of the North Sea. In addition to its contribution to the increase in delphinid diversity at that time, this record confirms the presence of members of this family in the North Atlantic realm during the Zanclean, as already attested by Lagenorhynchus harmatuki and Stenella rayi from the east coast of North America (Whitmore and Kaltenbach, 2008). Interestingly, all named late Miocene delphinids come from the Pacific Ocean (Japan and Peru; Pilleri and Siber, 1989; Murakami et al., 2014; Kimura and Hasegawa, 2020; Table 2), supporting the hypothesis that the family originated there before dispersing in the Southern Ocean (Australodelphis mirus; Fordyce et al., 2002) and the North Atlantic, North Sea, and Mediterranean (but see Murakami et al., 2014, for alternate biogeographic scenarios). The addition of a new delphinid species for the North Sea only slightly attenuates the predominance of Italian records for the Pliocene (seven species; Bianucci, 1996, 2005, 2013; Table 2).

Focusing on the North Sea, it should be noted that delphinoids in general are rare in early Pliocene deposits of that region; in addition to Pliodelphis doelensis, only one phocoenid, Brabocetus gigaseorum, and one unnamed monodontid have been described so far, each on the basis of a single specimen (Lambert and Gigase, 2007; Colpaert et al., 2015), suggesting that deposits of the Kattendijk Formation are not optimal for the record of these small to medium size delphinoids. The situation in the North Sea supports the idea that the rarity of Pliocene delphinids, as observed worldwide except for Italy, could at least be partly explained by the lack of adequate deposits (Bianucci, 2013). The effect of rock availability as a potential bias for past cetacean diversity has been previously tested at different scales (Uhen and Pyenson, 2007; Marx and Uhen, 2010); however, those analyses took account of the map area of continental shelf rocks and the total number of fossiliferous marine formations for a given time bin, respectively, therefore not allowing for the discrimination of marine deposits corresponding to different habitats (e.g. pelagic, neritic, littoral, and estuarine). The hypothesis that late Miocene and early Pliocene delphinids predominantly occupied more pelagic habitats, a feature that could also explain their limited record in shelf deposits worldwide, should thus be further tested, for example with the help of stable isotope and ecomorphological analyses (see Gillet et al., 2019). An improved fossil record, a more precise chronostratigraphic context for several Pliocene species, and the assessment of the phylogenetic affinities of more fragmentarily known species will be needed to better characterize the late Miocene and Pliocene delphinid radiations and extinctions, as well as their physical and biological drivers, ultimately leading to the most species-rich cetacean family (e.g. Fordyce et al., 2002; Bianucci, 2013; Marx et al., 2016; Bohrer do Amaral et al., 2018). New early delphinids, like the small $P$. doelensis, also have the potential to reveal the degree of morphological disparity (including size) at early stages of the evolutionary history of this highly disparate clade (Galatius et al., 2020).

More work is also needed to further test the affinities of extinct species that have been previously referred to extant genera (Lagenorhynchus harmatuki, Orcinus citoniensis, Stenella rayi, Tursiops oligodon, and Tursiops osennae). Indeed, either these referrals were not tested in a phylogenetic analysis (though occasionally openly questioned, for example for T. oligodon, later referred to the Pliocene genus Hemisyntrachelus; Post and Bosselaers, 2005) or the extinct species ( $S$. rayi and T. osennae) proved only distantly related to the proposed extant genus in recent phylogenetic analyses (Bianucci, 2005, 2013; Aguirre-Fernández et al., 2009; Murakami et al., 2014; Kimura and Hasegawa, 2020).

Data availability. All data and results are presented in the main text, tables, and figures.

Author contributions. $\mathrm{AB}$ and OL designed the experiments, carried them out, and prepared the manuscript, figures, and tables.

Competing interests. The authors declare that they have no conflict of interest.

Acknowledgements. We would like to thank Sébastien Bruaux, Georges Lenglet, and Olivier Pauwels (IRSNB), Giovanni Bianucci (MP), R. Ewan Fordyce (OU), David J. Bohaska, James G. Mead, Charles W. Potter, and Nicholas D. Pyenson (USNM), Lawrence G. Barnes and Vanessa R. Rhue (LACM), Adri G. Rol (ZMA), and Hein van Grouw (NNML) for providing access to the specimens under their care. Many thanks to Giovanni Bianucci for providing photos of Lagenorhynchus harmatuki USNM 206098, Stenella rayi USNM 182930, and many extant delphinid crania and to Mark Bosselaers for photos of the holotype of Tursiops oligodon SMNK-Pal 3841. We also thank the two reviewers, Gabriel Aguirre-Fernández and Oliver Hampe, and the editor Torsten Scheyer for their constructive comments and useful suggestions. This study has been performed during an Erasmus traineeship of $\mathrm{AB}$ (at that time a student of the Università di Pisa) at the IRSNB between November 2019 and April 2020. 
Financial support. This research has been supported by the Erasmus + Programme for Education of the EU (grant 1459/2019).

Review statement. This paper was edited by Torsten Scheyer and reviewed by Oliver Hampe and Gabriel Aguirre-Fernández.

\section{References}

Aguirre-Fernández, G., Barnes, L. G., Aranda-Manteca, F. J., and Fernández-Rivera, J. R.: Protoglobicephala mexicana, a new genus and species of Pliocene fossil dolphin (Cetacea; Odontoceti; Delphinidae) from the Gulf of California, Mexico, Bol. Soc. Geol. Mexicana, 61, 245-265, 2009.

Arnold, P., and Heinsohn, G.: Phylogenetic status of the Irrawady dolphin Orcaella brevirostris (Owen, in Gray): a cladistic analysis, Mem. Queensland Mus., 39, 141-204, 1996.

Barnes, L. G.: Outline of eastern North Pacific fossil cetacean assemblages, Syst. Zool., 25, 321-343, 1976.

Barnes, L. G.: Miocene and Pliocene Albireonidae (Cetacea, Odontoceti), rare and unusual fossil dolphins from the eastern North Pacific Ocean, Nat. Hist. Mus. Los Angeles County Sci. Series, 41, 99-152, 2008.

Bianucci, G.: The Odontoceti (Mammalia Cetacea) from Italian Pliocene. Systematics and phylogenesis of Delphinidae, Palaeontographia Italica, 83, 73-167, 1996.

Bianucci, G.: Arimidelphis sorbinii a new small killer whale-like dolphin from the Pliocene of Marecchia River (Central Eastern Italy) and a phylogenetic analysis of the Orcininae (Cetacea: Odontoceti), Riv. Italiana Paleontol. Stratigr., 111, 329-344, 2005.

Bianucci, G.: Septidelphis morii, n. gen. et sp., from the Pliocene of Italy: New evidence of the explosive radiation of true dolphins (Odontoceti, Delphinidae), J. Vertebr. Paleontol., 33, 722-740, 2013.

Bianucci, G., Vaiani, S. C., and Casati, S.: A new delphinid record (Odontoceti, Cetacea) from the Early Pliocene of Tuscany (Central Italy): systematics and biostratigraphic considerations, Neues Jahrb. Geol. Paläontol., 254, 275-292, 2009.

Bisconti, M.: Skull morphology and phylogenetic relationships of a new diminutive balaenid from the lower Pliocene of Belgium, Palaeontology, 48, 793-816, 2005.

Bisconti, M. and Bosselaers, M.: Fragilicetus velponi: a new mysticete genus and species and its implications for the origin of Balaenopteridae (Mammalia, Cetacea, Mysticeti), Zool. J. Linnean Soc., 177, 450-474, 2016.

Bisconti, M. and Bosselaers, M. E.: A new balaenopterid species from the Southern North Sea Basin informs about phylogeny and taxonomy of Burtinopsis and Protororqualus (Cetacea, Mysticeti, Balaenopteridae), PeerJ, 8, e9570, https://doi.org/10.7717/peerj.9570, 2020.

Bisconti, M., Lambert, O., and Bosselaers, M.: Revision of "Balaena" belgica reveals a new right whale species, the possible ancestry of the northern right whale, Eubalaena glacialis, and the ages of divergence for the living right whale species, PeerJ, 5, e3464, https://doi.org/10.7717/peerj.3464, 2017.
Boessenecker, R. W.: A new marine vertebrate assemblage from the Late Neogene Purisima Formation in Central California, part II: Pinnipeds and cetaceans, Geodiversitas, 35, 815-940, 2013.

Bohrer do Amaral, K., Amaral, A. R., Fordyce, R. E., and Moreno, I. B.: Historical biogeography of Delphininae dolphins and related taxa (Artiodactyla: Delphinidae), J. Mamm. Evol., 25, 241 259, 2018.

Brisson, M.-J.: Regnum Animale in classes IX distributum, sine synopsis methodica, Theodorum Haak, Paris, 296 pp., 1762.

Chen, I., Chou, L.-S., Chen, Y.-J., and Watson, A.: The maturation of skulls in postnatal Risso's dolphins (Grampus griseus) from Taiwanese waters, Taiwania, 56, 177-185, 2011.

Churchill, M., Geisler, J. H., Beatty, B. L., and Goswami, A.: Evolution of cranial telescoping in echolocating whales (Cetacea: Odontoceti), Evolution, 72, 1092-1108, 2018.

Colpaert, W., Bosselaers, M., and Lambert, O.: Out of the Pacific: a second fossil porpoise from the Pliocene of the North Sea Basin, Acta Palaeontol. Polonica, 60, 1-10, 2015.

Committee on Taxonomy: List of marine mammal species and subspecies, Society for Marine Mammalogy, available at: http://www.marinemammalscience.org, last access: 11 December 2020 .

de Muizon, C.: Les relations phylogénétiques des Delphinida, Ann. Paléontol., 74, 159-227, 1988a.

de Muizon, C.: Les vertébrés fossiles de la Formation Pisco (Pérou). Troisième partie: Les Odontocètes (Cetacea, Mammalia) du Miocène, Trav. Inst. Français Etudes Andines, 42, 1-244, 1988b.

de Muizon, C. and Domning, D. P.: The anatomy of Odobenocetops (Delphinoidea, Mammalia), the walrus-like dolphin from the Pliocene of Peru and its palaeobiological implications, Zool. J. Linn. Soc., 134, 423-452, 2002.

De Schepper, S., Head, M. J., and Louwye, S.: Pliocene dinoflagellate cyst stratigraphy, palaeoecology and sequence stratigraphy of the Tunnel-Canal Dock, Belgium, Geol. Mag., 146, 92-112, 2009.

Dewaele, L., Peredo, C. M., Meyvisch, P., and Louwye, S.: Diversity of late Neogene Monachinae (Carnivora, Phocidae) from the North Atlantic, with the description of two new species, R. Soc. Open Sci., 5, 172437, https://doi.org/10.1098/rsos.172437, 2018

Ehret, D. J., McFadden, B. J., Jones, D. S., DeVries, T. J., Foster, D. A., and Salas-Gismondi, R.: Origin of the white shark Carcharodon (Lamniformes: Lamnidae) based on recalibration of the Upper Neogene Pisco Formation of Peru, Palaeontology, 55, 1139-1153, 2012.

Fettuccia, D. d. C., Da Silva, V. M. F., and Simões-Lopes, P. C.: Non-metric characters in two species of Sotalia (Gray, 1866) (Cetacea, Delphinidae), Brazilian J. Biol., 69, 907-917, 2009.

Flower, W. H.: Description of the skeleton of Inia geoffrensis and the skull of Pontoporia blainvillii, with remarks on the systematic position of these animals in the Order Cetacea, Trans. Zool. Soc. London, 6, 87-116, 1867.

Fordyce, R. E. and de Muizon, C.: Evolutionary history of cetaceans: a review, in: Secondary adaptation of tetrapods to life in water, edited by: Mazin, J.-M. and de Buffrénil, V., Verlag Dr. Friedrich Pfeil, München, 169-233, 2001.

Fordyce, R. E., Quilty, P. G., and Daniels, J.: Australodelphis mirus, a bizarre new toothless ziphiid-like fossil dolphin (Cetacea: Delphinidae) from the Pliocene of Vestfold Hills, East Antarctica, Antarctic Sci., 14, 37-54, 2002. 
Fraser, F. C. and Purves, P. E.: Hearing in cetaceans: Evolution of the accessory air sacs and the structure of the outer and middle ear in recent cetaceans, Bulletin of the British Museum (Natural History), Zoology, 7, 1-140, 1960.

Galatius, A.: Paedomorphosis in two small species of toothed whales (Odontoceti): how and why?, Biol. J. Linnean Soc., 99, 278-295, 2010.

Galatius, A., Racicot, R., McGowen, M., and Olsen, M. T.: Evolution and diversification of delphinid skull shapes, IScience, 23, 101543, https://doi.org/10.1016/j.isci.2020.101543, 2020.

Gillet, A., Frédérich, B., and Parmentier, E.: Divergent evolutionary morphology of the axial skeleton as a potential key innovation in modern cetaceans, Proc. R. Soc. B, 286, 20191771, https://doi.org/10.1098/rspb.2019.1771, 2019.

Godfrey, S. J.: On the olfactory apparatus in the Miocene odontocete Squalodon sp. (Squalodontidae), C. R. Palevol., 12, 519530, 2013.

Gray, J. E.: On the natural arrangement of vertebrose animals, London Med. Repository, 15, 296-310, 1821.

Ichishima, H.: The ethmoid and presphenoid of cetaceans, J. Morphol., 277, 1661-1674, https://doi.org/10.1002/jmor.20615, 2016.

Ichishima, H. and Kimura, M.: Haborophocoena toyoshimai, a new early Pliocene porpoise (Cetacea: Phocoenidae) from Hokkaido, Japan, J. Vertebr. Paleontol., 25, 655-664, 2005.

Ichishima, H., Furusawa, H., Tachibana, M., and Kimura, M.: First monodontid cetacean (Odontoceti, Delphinoidea) from the early Pliocene of the north-western Pacific Ocean, Pap. Palaeontol., 5, 323-342, 2019.

Jefferson, T. A. and LeDuc, R.: Delphinids, overview, in: Encyclopedia of Marine Mammals, Third edition, Elsevier, London, 242246, 2018.

Kimura, T., and Hasegawa, Y.: Norisdelphis annakaensis, a new Miocene delphinid from Japan, J. Vertebr. Paleontol., 40, e1762628, https://doi.org/10.1080/02724634.2020.1762628, 2020.

Laeta, M., Ruenes, G. F., Siciliano, S., Oliveira, J. A., and Galatius, A.: Variation in cranial asymmetry among the Delphinoidea, Biol. J. Linn. Soc., 132, 414-430, 2021.

Lambert, O. and Gigase, P.: A monodontid cetacean from the Early Pliocene of the North Sea, Bull. Inst. R. Sci. Nat. Belgique Sci. Terre, 77, 197-210, 2007.

Lambert, O. and Louwye, S.: A new early Pliocene species of Mesoplodon: a calibration mark for the radiation of this speciesrich beaked whale genus, J. Vertebr. Paleontol., 36, e1055754, https://doi.org/10.1080/02724634.2015.1055754, 2016.

LeDuc, R. G., Perrin, W. F., and Dizon, A. E.: Phylogenetic relationships among the delphinid cetaceans based on full cytochrome $b$ sequence, Mar. Mamm. Sci., 15, 619-648, 1999.

Louwye, S., Head, M. J., and De Schepper, S.: Dinoflagellate cyst stratigraphy and palaeoecology of the Pliocene in northern Belgium, southern North Sea Basin, Geol. Mag., 141, 353-378, 2004.

Marino, L., McShea, D. W., and Uhen, M. D.: Origin and evolution of large brains in toothed whales, Anat. Rec., 281, 1247-1255, 2004.

Marx, F. G. and Fordyce, R. E.: Baleen boom and bust: a synthesis of mysticete phylogeny, diversity and disparity, R. Soc. Open Sci., 2, 140434, https://doi.org/10.1098/rsos.140434, 2015.
Marx, F. G. and Uhen, M. D.: Climate, critters, and cetaceans: Cenozoic drivers of the evolution of modern whales, Science, 327, 993-996, 2010.

Marx, F. G., Lambert, O., and Uhen, M. D.: Cetacean paleobiology, Topics in Paleobiology, edited by: Benton, M., John Wiley \& Sons, Chichester, UK, 319 pp., 2016.

McGowen, M. R., Spaulding, M., and Gatesy, J.: Divergence date estimation and a comprehensive molecular tree of extant cetaceans, Mol. Phylogenet. Evol., 53, 891-906, 2009.

McGowen, M. R., Tsagkogeorga, G., Álvarez-Carretero, S., dos Reis, M., Struebig, M., Deaville, R., Jepson, P. D., Jarman, S., Polanowski, A., and Morin, P. A.: Phylogenomic resolution of the cetacean tree of life using target sequence capture, Syst. Biol., 69, 479-501, 2020.

Mead, J. G. and Fordyce, R. E.: The therian skull: a lexicon with emphasis on the odontocetes, Smithsonian Contrib. Zool., 627, 1-248, 2009.

Murakami, M., Shimada, C., Hikida, Y., Soeda, Y., and Hirano, H.: Eodelphis kabatensis, a new name for the oldest true dolphin Stenella kabatensis Horikawa, 1977 (Cetacea, Odontoceti, Delphinidae), from the upper Miocene of Japan, and the phylogeny and paleobiogeography of Delphinoidea, J. Vertebr. Paleontol., 34, 491-511, 2014.

Perrin, W. F.: Variation of spotted and spinner porpoise (genus Stenella) in the eastern Pacific and Hawaii, Bulletin of the Scripps Institution of Oceanography University of California, San Diego La Jolla, California, 21, 1-206, 1975.

Pilleri, G. and Siber, H. J.: Neuer Delphinid (Cetacea, Odontoceti) aus der Pisco-Formation Perus, in: Beiträge zur Paläontologie der Cetaceen Perus, edited by: Pilleri, G., Hirnanatomisches Institut der Universität Bern, Bern, Switzerland, 165-175, 1989.

Post, K. and Bosselaers, M.: Late Pliocene occurrence of Hemisyntrachelus (Odontoceti, Delphinidae) in the southern North Sea, Deinsea, 11, 29-46, 2005.

Post, K. and Kompanje, E. J. O.: A new dolphin (Cetacea, Delphinidae) from the Plio-Pleistocene of the North Sea, Deinsea, 14, 1-12, 2010.

Ray, C. E.: Geography of phocid evolution, Syst. Zool., 25, 391406, 1976.

Ridgway, S. H. and Harrison, R.: Handbook of marine mammals, Vol. 5: The first book of dolphins, Academic Press, London, 1994.

Ridgway, S. H. and Harrison, R.: Handbook of marine mammals, Vol. 6: The second book of dolphins and the porpoises, Academic Press, London, 1999.

Ross, G. J. B.: The smaller cetaceans of the south east coast of southern Africa, Annals of the Cape Provincial Museums of Natural History, 15, 173-410, 1984.

Steeman, M. E., Hebsgaard, M. B., Fordyce, R. E., Ho, S. Y. W., Rabosky, D. L., Nielsen, R., Rahbek, C., Glenner, H., Sørensen, M. V., and Willerslev, E.: Radiation of extant cetaceans driven by restructuring of the oceans, Syst. Biol., 58, 573-585, 2009.

Uhen, M. D.: New protocetid whales from Alabama and Mississippi, and a new cetacean clade, Pelagiceti, J. Vertebr. Paleontol. 28, 589-593, 2008.

Uhen, M. D. and Pyenson, N. D.: Diversity estimates, biases, and historiographic effects: resolving cetacean diversity in the Tertiary, Palaeontol, Electronica, 10, 1-22, 2007. 
Vélez-Juarbe, J. and Pyenson, N. D.: Bohaskaia monodontoides, a new monodontid (Cetacea, Odontoceti, Delphinoidea) from the Pliocene of the western North Atlantic Ocean, J. Vertebr. Paleontol., 32, 476-484, 2012.
Whitmore Jr., F. C. and Kaltenbach, J. A.: Neogene Cetacea of the Lee Creek Phosphate Mine, North Carolina, Virginia Mus. Nat. Hist. Spec. Publ., 14, 181-269, 2008. 